\title{
Corrigendum
}

\section{Impact of COVID-19 on Traditional Healthcare Associated Infection Prevention Efforts - CORRIGENDUM}

In the above mentioned published article by Stevens et $\mathrm{al}^{1}$, the authors state that the Centers for Medicare and Medicaid Services (CMS) suspended penalties associated with the Hospital-Acquired Condition (HAC) Reduction Program temporarily; it is more accurate to state that the CMS has made data reporting for the fourth quarter of 2019 and the first 2 quarters of 2020 optional. For the HAC Reduction Program, "if data from January 1, 2020 - March 31, 2020 (Q1) is submitted, it will be used for scoring in the program."”

\section{References}

1. Stevens MP, Doll M, Pryor R, Godbout E, Cooper K, Bearman G. Impact of COVID-19 on Traditional Healthcare Associated Infection Prevention Efforts. Infect Control Hosp Epidemiol 2020 Apr 29 [Epub ahead of print]. doi: 10.1017/ice.2020.141.

2. Centers for Medicare and Medicaid Services press release. CMS announces relief for clinicians, providers, hospitals and facilities participating in quality reporting programs in response to COVID-19. Centers for Medicare and Medicaid Services website. https://www.cms.gov/newsroom/press-releases/cms-announces-reliefclinicians-providers-hospitals-and-facilities-participating-quality-reporting. Updated March 22, 2020. Accessed April 30, 2020. 